\title{
Importancia del uso de recursos didácticos en el proceso de enseñanza y aprendizaje de las ciencias biológicas para la estimulación visual del estudiantado
}

\author{
Importance of the Use of Teaching Resources in Teaching and Learning Biological \\ Science for Visual Stimulation of Students
}

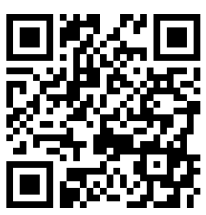

\author{
Josmary Celinda Suárez-Ramos ${ }^{1}$ \\ Universidad Pedagógica Experimental Libertador \\ Monagas, Venezuela \\ josmary.suarez@hotmail.com \\ http://orcid.org/0000-0003-0910-1441
}

Recibido 26 de julio de 2015 • Corregido 3 de diciembre de 2016 • Aceptado 10 de abril de 2017

\begin{abstract}
Resumen: El presente artículo tiene como objetivo realizar una revisión bibliográfica en fuentes documentales que aborden aspectos relacionados con la importancia del uso de recursos didácticos en el proceso de enseñanza y aprendizaje de las ciencias biológicas, hace énfasis en la estimulación visual del estudiantado, considera importantes informaciones en el ámbito de las ciencias biológicas, la pedagogía y la didáctica. Mediante una revisión sistemática se seleccionaron fuentes bibliográficas y electrónicas, dichas fuentes son de un período comprendido entre el año 1983 hasta el 2013. Se describirán algunos de los principales recursos didácticos que causan mayor impacto visual en el estudiantado y se traducen en aprendizaje significativo mediante su incorporación en la corteza cerebral, ya que que los hallazgos apuntan a que el aprendizaje de los individuos está mediado por el sistema nervioso y los órganos sensoriales, y estudios han comprobado que el sentido de la vista es el sistema de representación primario de la mayoría de los seres humanos, y las estrategias de enseñanza que combinan la vista con la audición tienen considerables posibilidades de ser más eficaces. Se concluye que el uso de recursos didácticos adecuados es indispensable para optimizar el aprendizaje del estudiantado en cuanto a los contenidos del área de las ciencias biológicas, por lo que se recomienda al personal docente considerar estas realidades al momento de planificar las estrategias para impartir sus clases.
\end{abstract}

Palabras claves: Recursos didácticos; aprendizaje visual; ciencias biológicas.

\footnotetext{
${ }^{1}$ Profesora de la especialidad de Biología, adscrita al Departamento de Ciencias Naturales de la UPEL-IPM, en el área de Biología de los Invertebrados, Fundamentos de Biología y Planificación Didáctica de los Aprendizajes.
} 
doi: http://dx.doi.org/10.15359/ree.21-2.22

URL: http://www.una.ac.cr/educare

CORREO: educare@una.cr

\begin{abstract}
This article aims to conduct a literature review on documentary sources approaching aspects related to the importance of the use of didactic resources in the teaching and learning process of biological sciences. The paper focuses on the visual stimulation of students, and considers important information in the field of biological sciences, pedagogy and didactics. Through a systematic review, bibliographical and electronic sources were selected; they were published in a period from 1983 to 2013. The article describes some of the main didactic resources producing greater visual impact in the students and turning into meaningful learning through their incorporation into the cerebral cortex. Findings suggest that the individuals' learning is mediated by the nervous system and the sensory organs. Likewise, studies have verified that the sense of sight is the system of primary representation for most human beings, and the teaching strategies combining vision with hearing have considerable possibilities of being more effective. It is concluded that the use of adequate didactic resources is indispensable to optimize students' learning in terms of content in the area of biological sciences. So it is recommended that teachers consider these realities when planning strategies to teach their classes.
\end{abstract}

Keywords: Didactic resources; visual learning; biological sciences.

\title{
Introducción
}

Todos los individuos, en condiciones normales, cuentan con sistemas perfectamente diseñados para la percepción y decodificación de información del entorno, que les permiten comprender el medio que los rodea, almacenar información y dar respuestas ante cualquier situación. Estos son el sistema nervioso y el sistema sensorial, este último constituido por los órganos utilizados para la apreciación de los sentidos: vista, oído, olfato, gusto y tacto.

El sistema nervioso se divide en sistema nervioso central, conformado por el encéfalo (cerebro, cerebelo y médula oblonga) y la médula espinal, encargados de procesar la información y producir las respuestas; y el sistema nervioso periférico, conformado por los nervios, cuya función es la transmisión tanto de los estímulos nerviosos al sistema nervioso central, como las respuestas generadas (también en forma de impulsos) hacia los órganos efectores, los que llevarán a cabo la acción pertinente. Tal como lo plantea, Latarjet y Ruiz (2004): "el sistema nervioso central comprende el conjunto de los centros y vías nerviosas reunidas en el encéfalo y la médula espinal. Está conectado a los diversos órganos por intermedio del sistema nervioso periférico formado por nervios craneales y espinales" (p. 150).

Por su parte, los órganos sensoriales, según Fuentes (2012), "se encargan de informarnos, mediante diversos procesos de captación de estímulos, acerca del ambiente que nos rodea; además, nos alertan sobre posibles cambios contrarios a nuestras necesidades. En general constan de un elemento receptor, otro transmisor y el área de percepción" (p. 146). Esta área de percepción se encuentra en la corteza cerebral, y es allí donde el fenómeno que se percibe a través de los sentidos se hace consciente. Es decir, los órganos sensoriales reciben la información del medio y la traducen en impulsos para que pueda ser asimilada por nuestro sistema nervioso.

De acuerdo con los órganos sensoriales, existen dos principales tipos de aprendizaje: el visual y el auditivo. De la Parra (2004) afirma que en un $40 \%$ de las personas predomina como

2

Los artículos de la Revista Electrónica Educare del Centro de Investigación y Docencia en Educación de la Universidad Nacional, Costa Rica, se comparten bajo términos de la Licencia Creative Commons: Reconocimiento, No Comercial, Sin Obra Derivada 3.0 Costa Rica. Las autorizaciones adicionales a las aquí delimitadas se pueden obtener en el correo: educare@una.cr 
estilo de aprendizaje primario el visual, mientras que un 30\% el auditivo y el otro $30 \%$ kinestésico. Esto se basa fundamentalmente en los estilos de aprendizaje o sistemas representativos descritos en la programación neurolingüística de John Grinder y Richard Bandler. Al respecto, O'Connor y Seymour (1995) plantea:

En la PNL las maneras como recogemos, almacenamos y codificamos la información en nuestra mente -ver, oír, sentir, gustar y oler- se conocen con el nombre de sistemas representativos... Los sistemas visual, auditivo y cinestésico son los sistemas representativos primarios empleados en la cultura occidental. Los sentidos del gusto $(G)$ y olfato $(O)$, no son tan importantes y a menudo se incluyen en el sentido cinestésico. Sirven, muchas veces, como nexos inmediatos y muy poderosos a las imágenes, sonidos y escenas asociados con ellos. (pp. 60-61)

Otros estudios establecen que el ser humano en condiciones normales aprende principalmente a través de los sentidos de la vista y el oído. Considerando los cinco sentidos, el porcentaje de priorización está distribuido de la siguiente manera: el gusto 1\%; el tacto 1,5\%; el olfato 3,5\%; el oído $11 \%$ y la vista $83 \%$. Además, plantean que la combinación de la estimulación oral y visual de manera simultánea permite retener un $85 \%$ de los datos después de tres horas, y un $65 \%$ de ellos después de tres días, cifras considerablemente mayores a las obtenidas cuando la forma de presentación de la información es oral o visual por separado, que alcanza en los datos retenidos después de tres días un $10 \%$ y un $20 \%$ respectivamente

Una parte de estudiantes con un alto nivel imaginativo logran aprender a través de la audición; sin embargo, este proceso generalmente es eficiente cuando el individuo tiene previamente en sus esquemas mentales imágenes relacionadas con el tema objeto de estudio. No obstante, cuando los temas son desconocidos para los individuos en cuestión el aprendizaje auditivo se dificulta. Al respecto Ausubel, Novak y Hanesian (1983) afirman que:

El aprendizaje del alumno depende de la estructura cognitiva previa que se relaciona con la nueva información, debe entenderse por 'estructura cognitiva', al conjunto de conceptos, ideas que un individuo posee en un determinado campo del conocimiento, así como su organización. (p. 18)

Según Ausubel et al. (1983), el aprendizaje significativo es contrario al memorístico, puesto que los contenidos no son incorporados de manera arbitraria, sino que las ideas deben ser relacionadas con alguna imagen o símbolo previamente existente en la estructura cognoscitiva del estudiante.

Cabe destacar que el aprendizaje significativo que describió Ausubel es desde el punto de vista biológico información procesada y almacenada en la memoria de largo plazo. Para que ese almacenamiento suceda, el cerebro debe revisar y codificar la información seleccionada, esto mediante el reconocimiento de patrones y de manera significativa se asocian los estímulos 
doi: http://dx.doi.org/10.15359/ree.21-2.22

URL: http://www.una.ac.cr/educare

CORREO: educare@una.cr

percibidos con las experiencias o conocimientos pasados. El hipocampo (parte del sistema límbico) se encarga de la formación y recuperación de recuerdos, además tiene la capacidad de retener nueva información e integrar varios aspectos de una experiencia, incluyendo imágenes, sonidos, aromas, texturas y sabores, con prioridad de los estímulos sensoriales preferenciales de cada individuo. Además, el hipocampo almacena las experiencias por categorías junto con otras semejantes, de esta manera se integra la información con otros conocimientos anteriormente almacenados en el cerebro (Solomon, Berg y Martin 2013).

Debido a que se ha comprobado que entre los estímulos sensoriales preferenciales en los seres humanos predominan los estímulos visuales, es pertinente, entonces, abordar la importancia de la estimulación visual estudiantil en el proceso de enseñanza y aprendizaje mediante el uso de recursos didácticos. En el caso de la presente revisión bibliográfica se hará énfasis en la enseñanza de los temas y contenidos de las ciencias biológicas en los diferentes niveles del sistema educativo.

En el abordaje del tema se desarrollarán aspectos como: el arte de educar, donde se destaca la importancia de la labor docente en cuanto a la formación académica y personal del estudiantado; la enseñanza de las ciencias biológicas, con mención de la amplitud de su objeto de estudio por tratarse de todo lo relacionado con los seres vivos; la creatividad como característica fundamental en la labor docente, pues esta permite una renovación constante de su práctica profesional, lo que se traduce en adaptabilidad y, por consiguiente, en mejoras para los procesos de enseñanza y aprendizaje; recursos didácticos en ciencias biológicas para la estimulación visual del estudiantado, impresión en la estructura cognitiva, se resalta la importancia del uso de recursos didácticos visuales que faciliten no solo la percepción y captación de la información mediante los fotorreceptores, sino también la codificación en la corteza cerebral y el almacenamiento de esa información en la memoria a largo plazo; recursos que causan un mayor impacto visual, con énfasis en las ilustraciones esquematizadas, los modelos didácticos, los mapas conceptuales, los mapas mentales y los esquemas; y el último aspecto, se enmarca en las tecnologías de la información y comunicación como herramienta educativa.

\section{El arte de educar}

Los docentes y las docentes son personas con una gran responsabilidad social, pues tienen la tarea de participar en la formación de la ciudadanía; es bien sabido que todos aquellos individuos que estudian en el sistema educativo de cualquier país deben ser orientados por más de una persona docente a lo largo de su vida, y ciertamente juegan un papel de marcada relevancia en los aprendizajes, la actitud, el comportamiento e incluso los rasgos que conforman la personalidad sus estudiantes.

No solo los contenidos académicos impartidos por el personal docente son capaces de marcar la vida de cada estudiante, sino también el ejemplo en cuanto a valores como la excelencia, la responsabilidad, el respeto, la tolerancia, la empatía, entre otros. Pues, los niños, las niñas y adolescentes tienden a tener suficiente percepción e incluso criticidad en cuanto a las personas que se encuentran a su alrededor, apropiándose de sus características, en algunos casos de manera inconsciente.

4

Josmary Celinda Suárez Ramos

Los artículos de la Revista Electrónica Educare del Centro de Investigación y Docencia en Educación de la Universidad Nacional, Costa Rica, se comparten bajo términos de la Licencia Creative Commons: Reconocimiento, No Comercial, Sin Obra Derivada 3.0 Costa Rica. Las autorizaciones adicionales a las aquí delimitadas se pueden obtener en el correo: educare@una.cr 
En consecuencia, el personal docente debe ser sumamente cauteloso y prudente en su accionar, si le interesa dejar en alto su ética profesional. Etimológicamente, según Castello y Mársico (1995), "el término 'educar' proviene del latín educare, que tiene el sentido básico de 'criar', 'alimentar', no sólo niños sino también animales. A partir de allí se desarrolla el sentido abstracto espiritual e intelectual de 'formar', 'instruir"' (p. 4). Por ende, el arte de educar está precisamente en instruir y conducir al estudiantado al aprendizaje, el cual implica no solo la adquisición de información, sino de conocimiento, y este no debería quedarse simplemente como un marco de referencia en la estructura cognitiva del sujeto: el conocimiento debe ser internalizado para ponerlo en práctica cuando las circunstancias lo requieran; en esto se basa el verdadero concepto de inteligencia que muchos tienden a confundir; es, pues, la inteligencia la capacidad de los individuos de aplicar los conocimientos adquiridos para la resolución de problemas y situaciones que se les presenten en la vida cotidiana.

\section{Enseñanza de las ciencias biológicas}

Existen diversas especialidades en las cuales se pueden formar aquellos individuos que quieren optar por un título universitario de profesorado, las cuales están vinculadas a las asignaturas o materias que se imparten en el sistema educativo de cada nación. Las ciencias biológicas o biología corresponden a una de esas especialidades. La biología es una ciencia amplia que se encarga del estudio de los seres vivos, considera la gran biodiversidad de nuestro planeta, que va desde los organismos unicelulares sencillos como las bacterias, otros también formados por una sola célula (pero no tan sencillos) como los protozoarios, hasta los pluricelulares, como por ejemplo: los hongos, plantas y animales. En este último reino están incluidos, a su vez, organismos tan variados como: poríferos, cnidarios, platelmintos, nematodos, anélidos, moluscos, equinodermos, artrópodos, peces, anfibios, reptiles, aves, mamíferos, donde se encuentran también los seres humanos, entre otros (este es un recorrido a grandes rasgos).

No obstante, las ciencias biológicas, además de estudiar las generalidades concernientes a los diferentes grupos de seres vivos, estudian ciertas áreas específicas, por lo cual se dividen en disciplinas, entre las cuales es posible mencionar: anatomía, fisiología, genética, citología, histología, morfología, etología. Asimismo, también se dividen de acuerdo con los diferentes grupos de organismos, por ejemplo: zoología, botánica, bacteriología, micología, y estas a su vez se subdividen en otras.

Ahora bien, pensando en la amplitud de aspectos que abarca esta ciencia, en la cual se estudian ciertos contenidos que, a pesar de estar relacionados con la cotidianidad, muchos son realmente poco conocidos a profundidad, ¿será posible explicar de manera teórica dichos aspectos, sin el uso de ningún tipo de recursos didácticos visuales?

Imaginemos intentar enseñar los siguientes contenidos sin utilizar recursos didácticos que estimulen el aprendizaje visual de quienes los aprenderán en las clases: forma, ubicación 
doi: http://dx.doi.org/10.15359/ree.21-2.22

URL: http://www.una.ac.cr/educare

CORREO: educare@una.cr

y función de las diferentes partes que constituyen cualquiera de los sistemas orgánicos de los diversos organismos pluricelulares; orgánulos existentes en las células eucariotas; diferencias morfológicas entre células animales y vegetales; ciclos biogeoquímicos que ocurren en nuestro planeta; ciclos biológicos de diferentes seres vivos; etapas de los procesos de división celular por mitosis y meiosis, formación de los gametos o células sexuales (gametogénesis); entre otros.

Jamás tendrá el mismo impacto en la estructura cognitiva de un individuo la simple descripción de una estructura o un proceso, que la observación de imágenes detalladas acompañadas de la explicación, y mucho menos cuando el tema abordado es totalmente desconocido para el sujeto, por lo que no tiene información previa relacionada que pueda asociar para lograr el aprendizaje significativo.

\section{La creatividad como característica fundamental en la labor docente}

Es pertinente, primeramente, definir lo que se conoce como creatividad. Menchén (1998) la define como"la capacidad para captar la realidad de manera singular, generando y expresando nuevas ideas, valores y significados" (p. 62). Esto nos indica claramente que la creatividad implica innovación, y lo que se va a producir, ya sea una idea o algún producto tangible, debe tener impreso el sello de su autoría, debe ser algo auténtico y original, aunque se tome como base algo previamente existente.

Para que el proceso de enseñanza conlleve a un verdadero aprendizaje es necesario que el personal docente o la persona que desea promover en otra la apropiación del conocimiento utilice estrategias creativas adaptadas a ciertos factores, como por ejemplo: el tipo de contenido que se desea impartir y los recursos con los cuales cuenta; pero es aún más importante estar consciente de quiénes son las personas a las cuales se va a dirigir la información, cuáles son sus edades aproximadas, su nivel académico, su contexto social. Pensemos un poco: no puede ser igual impartir una clase de educación sexual a unos niños y niñas con edades comprendidas entre 10 y 12 años, que a personas adultas con edades entre 30 y 40 años.

Los tiempos han cambiado, las generaciones son diferentes unas de las otras, la que tenemos hoy es una generación tecnológica, fuertemente influenciada por las tecnologías de información y comunicación, que ahora -más que antes- están al alcance de un gran número de personas dentro de la sociedad. La niñez y adolescencia actuales tienen una notable facilidad para el manejo de la tecnología y conocen una gran variedad de programas y aplicaciones que probablemente gran cantidad de docentes desconocen. ¿Será adecuado que se continúen utilizando las mismas estrategias de enseñanza y técnicas de evaluación que hace diez años?

Los grupos docentes tanto de ciencias biológicas, como de cualquier otra área, están obligados a una actualización constante tanto del conocimiento (puesto que en muchas oportunidades surgen nuevas informaciones de relevancia) como en las estrategias a utilizar, ya que deben adaptarse al contexto histórico y social que se vive, y no deberían estar desfasados.

6 
La creatividad juega un papel fundamental en esta renovación del pensamiento. Existen docentes con muchos años de servicio, con la acostumbre de impartir sus clases de la misma manera que cuando iniciaron su labor, ignorando la realidad que está fuera del aula de clases, lo que puede ocasionar que sus estudiantes se distraigan con facilidad y no asimilen lo que se les está explicando.

Un gran número de personas consideran que la creatividad es innata por lo que no se puede enseñar, pero esto no es cierto. Al respecto, De Bono (1994) plantea que la creatividad es "una habilidad más que podemos cultivar y desarrollar" (p. 66). Por lo tanto, la creatividad como habilidad o destreza puede ser trabajada por cada individuo para que se pueda lograr el pensamiento creativo, pero para ello debe existir motivación.

Entre las características de la persona creativa deben encontrarse: la fluidez, la flexibilidad, la originalidad y la capacidad de redefinición (Muñoz, 1994). Si consideramos que estamos realmente escasos en alguna o algunas de estas características, podemos trabajar a voluntad para fomentarla.

\section{Recursos didácticos en ciencias biológicas para la estimulación visual del estudiantado, impresión en la estructura cognitiva}

El personal docente de ciencias biológicas que acostumbra impartir clases sin utilizar ningún tipo de recurso didáctico, en muchos casos puede lograr lo que considera son resultados favorables, quizás reflejados en calificaciones positivas de algunos de sus estudiantes; sin embargo, es probable que esos resultados sean producto de un aprendizaje memorístico, el cual solo está presente en la estructura cognitiva a corto plazo, generalmente al finalizar la respectiva evaluación tienden a olvidar la información, y se supone que la intención docente debe ser que sus estudiantes logren internalizar el conocimiento para poder ponerlo en práctica o utilizarlo cuando lo crean pertinente en cualquier momento de su vida.

Está comprobado que en nuestra corteza cerebral tenemos áreas específicas para cada uno de los impulsos nerviosos que provienen de nuestros órganos sensoriales, al respecto Hickman et. al. (2006) plantean:

La corteza tiene unas áreas motoras y sensoriales separadas. Las áreas motoras controlan los movimientos de los músculos voluntarios, y la corteza sensorial es el centro de la percepción consciente del tacto, la presión, el dolor, la temperatura y el gusto. La vista, el olfato, el oído y la capacidad del habla dependen de regiones exclusivamente sensoriales o exclusivamente motoras en áreas concretas de los lóbulos cerebrales. (p. 832)

Por ejemplo, los estímulos percibidos por el oído son transformados en impulsos nerviosos y conducidos por el nervio auditivo hasta los lóbulos temporales de nuestro cerebro; los estímulos percibidos por los ojos, también se transforman en impulsos nerviosos y se conducen por el 
doi: http://dx.doi.org/10.15359/ree.21-2.22

URL: http://www.una.ac.cr/educare

CORREO: educare@una.cr

nervio óptico hasta el lóbulo occipital del cerebro. Una vez que los impulsos nerviosos llegan a la corteza cerebral, allí son decodificados, y se genera una respuesta, pero además la información es almacenada para ser empleada posteriormente. Incluso, Hickman et. al. (2006) también hacen referencia a que para la década de 1930, un neurocirujano canadiense, de nombre Wilder Penfield realizó importantes trabajos en relación con esto y diseñó un mapa en el cual se evidencia la disposición de las cortezas sensoriales y motoras, donde se muestran la localización de los centros terminales sensoriales de distintas partes del cuerpo y sus respectivos tractos motores (p. 833).

¿Alguna vez ha escuchado una canción que tenía años si escuchar o recordar, pero descubre que aún se encuentra guardada completamente en su cerebro, pues de inmediato la recuerda en su totalidad, o por lo menos gran parte de ella? Esto se debe a que nuestro cerebro, perfectamente diseñado, tiene la capacidad de almacenar una gran cantidad de información. A pesar de que los grupos de especialistas en informática, electrónica y ciencias afines han ideado equipos cada día más sofisticados y eficientes, con cada vez más funciones y capacidad de almacenamiento, aún no han logrado igualar las habilidades tan maravillosas que tienen nuestros cerebros, capaces de recibir estímulos tan diversos a través de los órganos sensoriales: podemos recibir, procesar y almacenar en la memoria a largo plazo innumerables estímulos químicos, mecánicos y electromagnéticos, y ningún equipo ideado por el ser humano ha podido reunir todas estas características.

Es necesario, pues, que los cuerpos docentes se aprovechen de estas capacidades que comparten los seres humanos en condiciones normales y estimulen los principales órganos sensoriales del aprendizaje, y con esto no me refiero solo al oído, sino a la combinación de este con nuestros fotorreceptores, es decir, los órganos de nuestra visión. El aprendizaje será más contundente y duradero cuando incite a ambos caminos sensoriales, ya que estimulará más áreas de la corteza cerebral de manera simultánea.

\section{Recursos que causan un mayor impacto visual}

Existen variados recursos que pueden ser utilizados al momento de abordar una clase de ciencias biológicas. Los más comunes son las ilustraciones o dibujos esquemáticos (ver Figura 1). Según Gómez (1995):

El dibujo se establece siempre como la fijación de un gesto que concreta una estructura, por lo que enlaza con todas las actividades primordiales de expresión y construcción vinculadas al conocimiento, a la descripción de ideas, las cosas y los fenómenos de interpretación basados en la explicación de su sentido por medio de sus configuraciones. (p. 17)

Puesto que en las ciencias biológicas se explican diversas estructuras anatómicas de gran variedad de seres vivos y es bastante práctico no solo mostrar las imágenes reales, sino también acompañarlas de ilustraciones en las cuales se esquematicen las partes que los constituyen, lo que facilita a su vez explicar las características de dichas partes y los procesos que se llevan a cabo en cada una de ellas. 
doi: http://dx.doi.org/10.15359/ree.21-2.22

URL: http://www.una.ac.cr/educare

CORREO: educare@una.cr

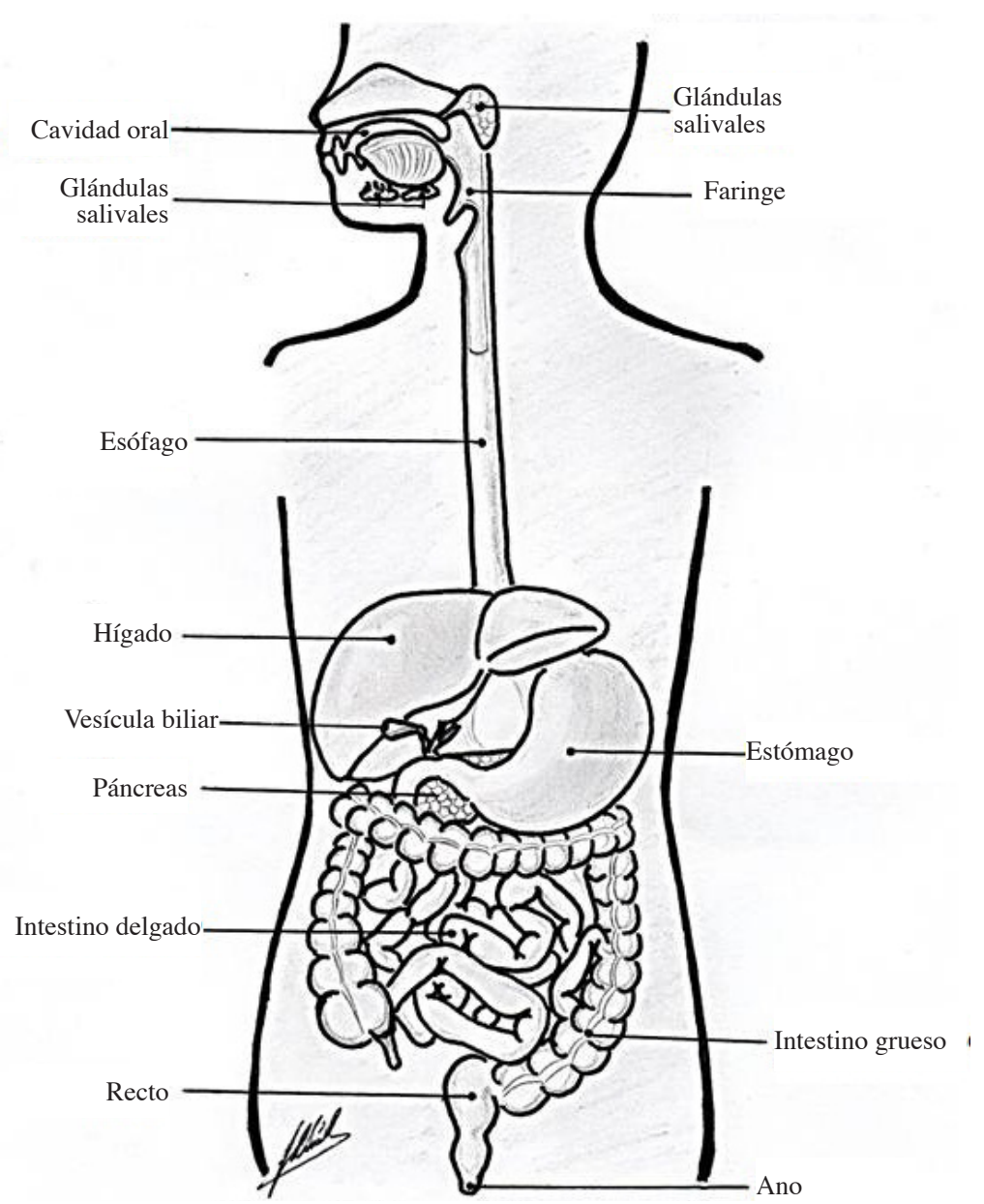

Figura 1: llustración esquemática.

Nota: Elaboración propia.

También los modelos didácticos son sumamente útiles para este tipo de casos (ver Figura 2), ya que muestran una visión más real y por supuesto, tridimensional de las estructuras anatómicas a estudiar. Se debe seleccionar este recurso para el aprendizaje cuando es necesario mirar objetos u organismos reales de muy grandes o muy pequeñas dimensiones, entre sus ventajas se encuentran la posibilidad de tocar y manipular las partes que conforman el modelo, pues muchos de ellos son desarmables, lo que a su vez desarrolla tanto la capacidad de observación como las destrezas para armar y desarmar objetos, y esto dinamiza la clase (López, 2012).

Además, en el caso específico de las ciencias biológicas y sus ramas, no solo el tamaño es un factor limitante para el estudio de determinadas estructuras sino también la imposibilidad de llevar el objeto real al aula de clase, por ejemplo, si el objeto de enseñanza es un sistema de órganos un modelo 
doi: http://dx.doi.org/10.15359/ree.21-2.22

URL: http://www.una.ac.cr/educare

CORREO: educare@una.cr

anatómico de este mismo es un recurso bastante útil, porque permite apreciar la forma y la ubicación de los órganos que lo constituyen y comparar la correspondencia en cuanto al tamaño de cada uno de ellos, incluso es posible estudiar con más detalle algún órgano en específico. Sin embargo, no en todas las instituciones educativas cuentan con estos, y son más difíciles de conseguir para el docente debido a sus altos costos (en el caso de los modelos comerciales), y su elaboración es más complicada.

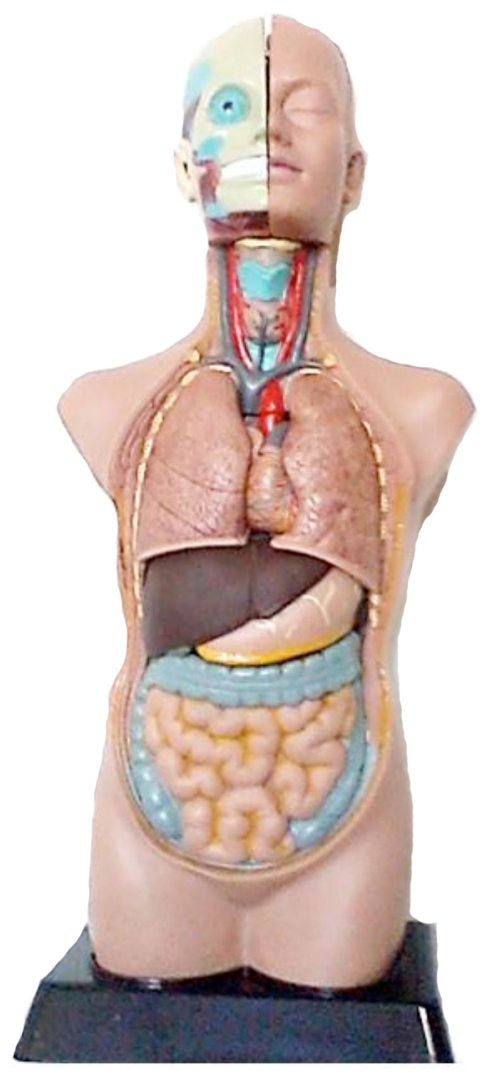

Figura 2: Modelo anatómico.

Nota: Fotografía tomada por la profesora Josmary Suárez, 2016

Otros temas no se adaptan a los recursos mencionados, por ejemplo, aquellos que explican conceptos, etapas de procesos y sus características. Para estos se pueden utilizar mapas conceptuales, los cuales permiten abordar temas extensos estructurados o desglosados en partes más simples enlazadas por líneas o flechas. Este recurso didáctico desarrollado por Novak en la década de 1970 con la finalidad de facilitar el aprendizaje significativo ha sido empleado en gran manera para la estructuración y representación de temas educativos. Stewart, Van Kirk y Rowell (1979) citado en González (1992) hacen hincapié en la importancia de este recurso en lo que es el diseño de material curricular, planificación instruccional y evaluación en el área de la Didáctica de las Ciencias Biológicas, esto de acuerdo a validaciones empíricas al respecto. 
Para realizarlos, es necesario ubicar el nombre del contenido a desarrollar preferiblemente en la parte superiory, a partir de este, ir jerarquizando las ideas, las cuales deben estar conectadas unas a otras (red de conexiones) (ver Figura 3). Esta manera de representar la información teórica impresiona más nuestra área visual y es más fácil de almacenar en la corteza cerebral en comparación con el texto continuo distribuido en párrafos. Los mapas conceptuales facilitan la organización lógica y estructurada de los contenidos de aprendizaje porque son útiles para seleccionar, extraer y separar la información más importante de aquella que es superficial y menos relevante, se integran las relaciones de un todo mediante relaciones de subordinación desarrollando ideas a través de un aprendizaje interrelacionado (López, 2012).

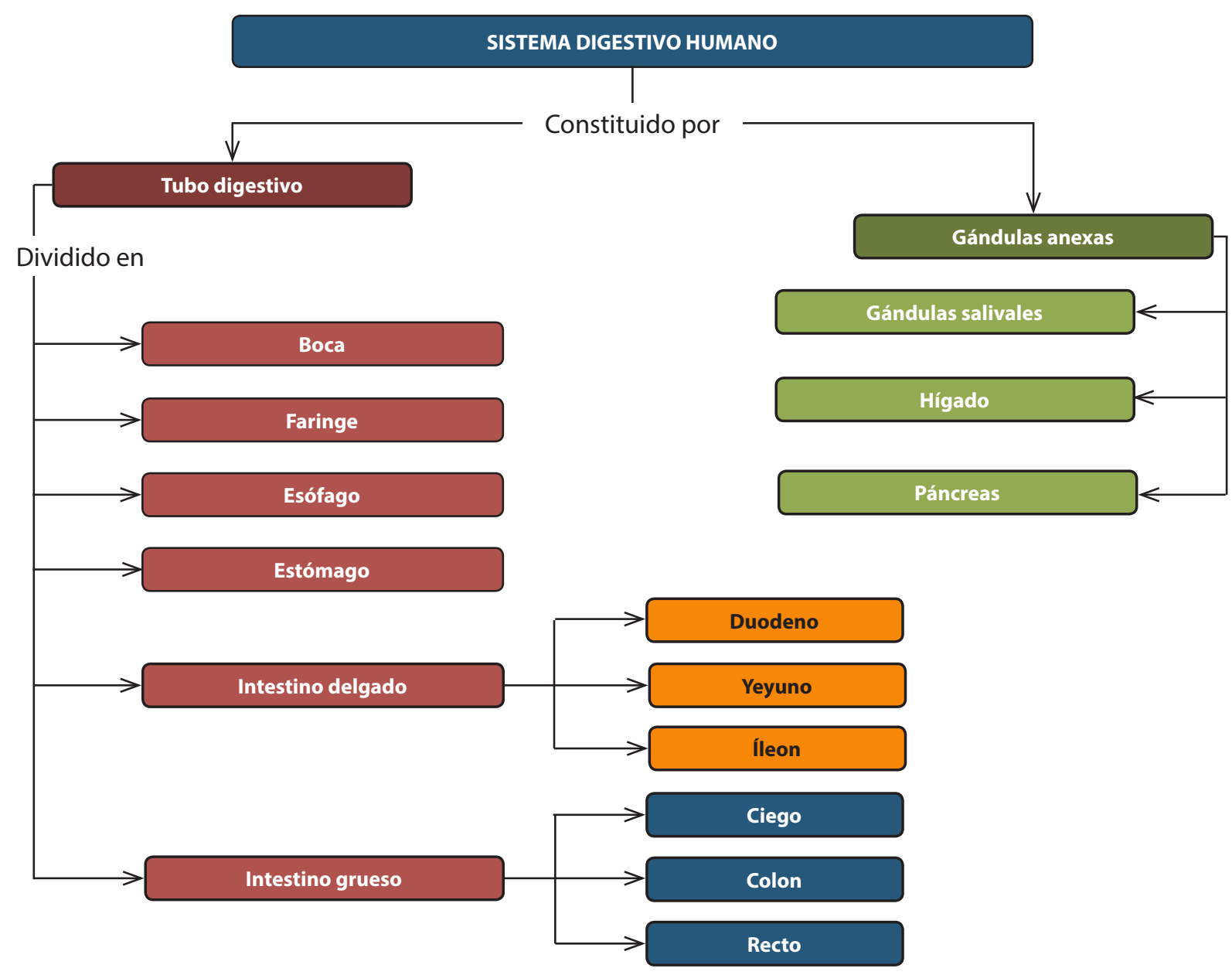

Figura 3: Mapa conceptual.

Nota: Elaboración propia. 
doi: http://dx.doi.org/10.15359/ree.21-2.22

URL: http://www.una.ac.cr/educare

CORREO: educare@una.cr

Los mapas mentales o cognitivos son otra opción sumamente interesante, porque organizan las ideas con palabras acompañadas de imágenes, por lo que permiten impresionar un mayor número de áreas cerebrales, si el mapa mental además de ser presentado es explicado oralmente se estimulan las áreas cerebrales del lenguaje oral y escrito, y el área de percepción espacial. Este recurso desarrollado por Tony Buzan, consiste, según López (2012), en:“una representación gráfica de un proceso holístico en su concepción y percepción, que facilita la toma de notas y los repasos efectivos... es una manera de generar, registrar, organizar y asociar ideas tal y como las procesa el cerebro humano" (p. 65). Para la elaboración de mapas mentales se debe colocar el título del tema a desarrollar en la parte central, preferiblemente acompañado de una imagen al respecto, luego colocar los subtítulos alrededor y unidos al título principal, por flechas, se recomienda que la información

se organice en el sentido de las agujas del reloj. Es importante colocar imágenes referentes a los aspectos que se han ubicado en el mapa mental (Ver Figura 4).

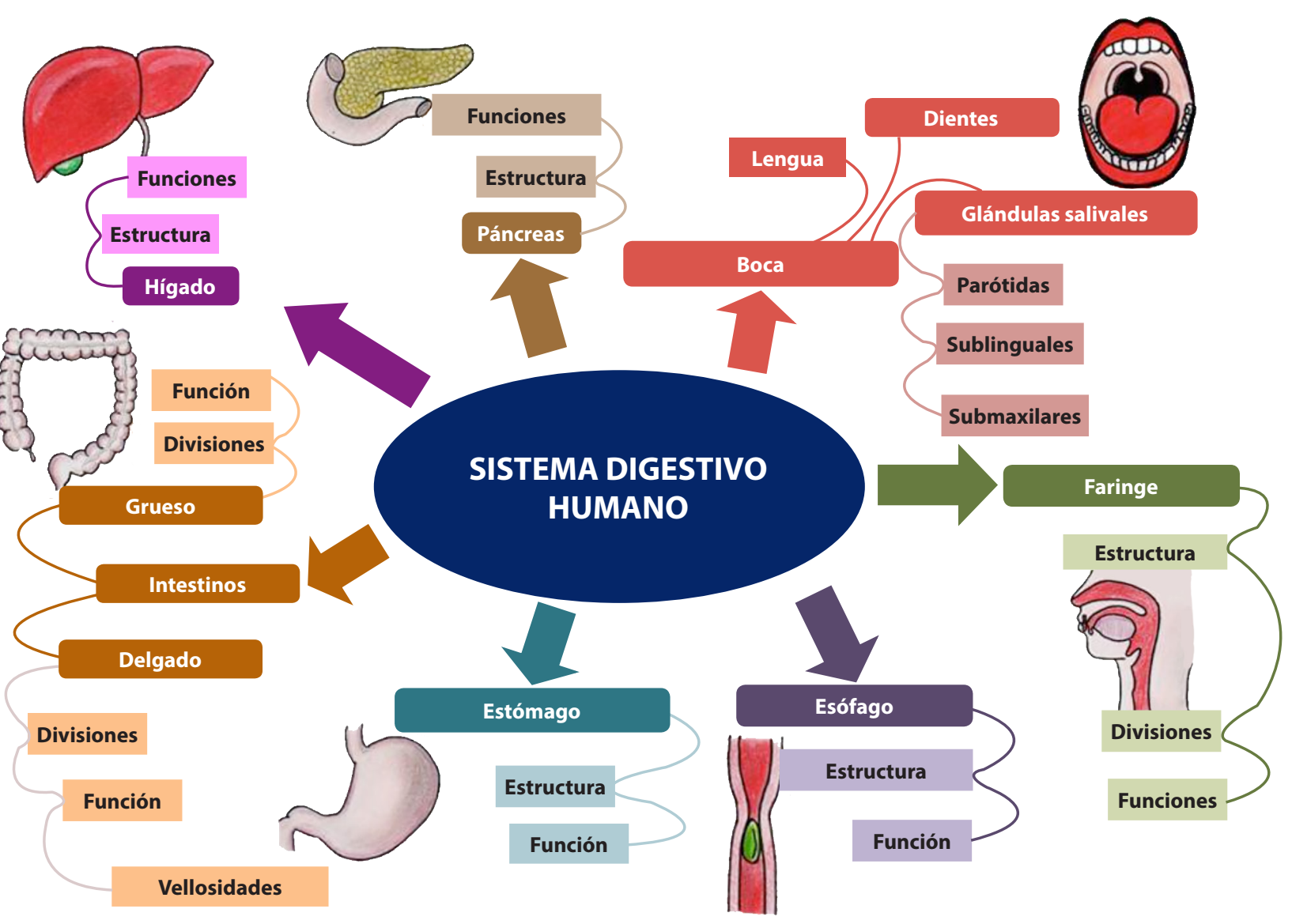

Figura 4: Mapa mental.

Nota: Elaboración propia. 
En los mapas mentales es necesario hacer énfasis en los aspectos más importantes o más amplios, manteniendo el orden jerárquico, este énfasis se logra con algún tipo de letra diferente o empleando colores que resalten. En la construcción de este recurso, la creatividad juega un papel fundamental, es válido el uso de colores diversos, distintos tipos de letras, flechas con formas diferentes, entre otros aspectos.

Los mapas mentales son construcciones subjetivas de cada individuo, es su manera de organizar sus esquemas mentales, dos personas pueden realizar mapas mentales increíblemente diferentes acerca de un mismo tema y basados en una misma información, en el caso de mapas conceptuales es mayor la probabilidad de coincidencias. Esta herramienta además de ser útil para explicar un tema, puede serlo aún más para que un estudiante se apropie del conocimiento, una buena estrategia podría ser solicitar a cada estudiante la construcción de su propio mapa mental.

Las representaciones esquemáticas o esquemas están constituidos por un resumen de algún tema en el que se destacan los aspectos más importantes de una forma capaz de ser captada por la vista sin mayor complicación, pueden ser utilizadas llaves que indiquen la relación entre ideas que van englobadas dentro de otras (ver Figura 5). En las ciencias biológicas este recurso puede ser aplicado eficientemente para cualquier tema, se puede emplear para la organización de información general o incluso para aspectos específicos y detallados.

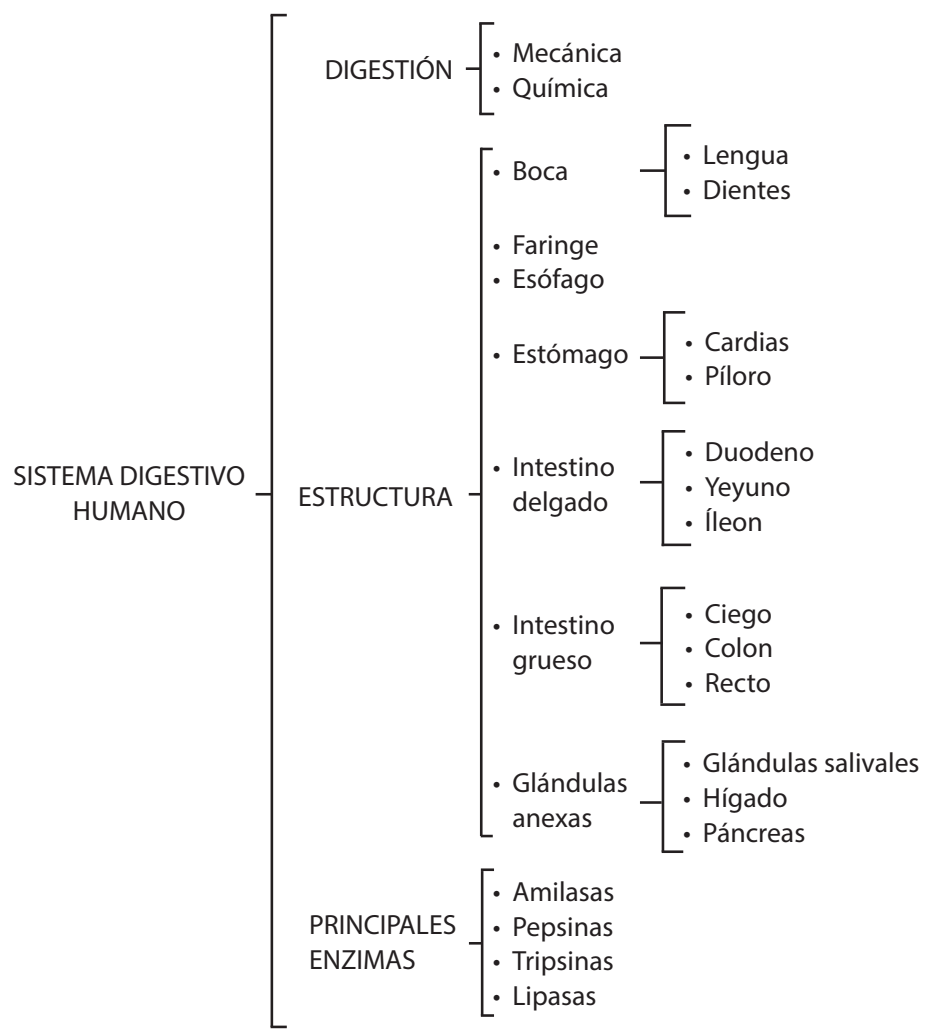

Figura 5: Elaboración propia. 
doi: http://dx.doi.org/10.15359/ree.21-2.22

URL: http://www.una.ac.cr/educare

CORREO: educare@una.cr

Los esquemas son elementos gráficos que permiten organizar la información, difieren de los mapas conceptuales en varios aspectos, entre ellos: contienen una mayor cantidad de texto, no emplean cuadros o figuras para encerrar los conceptos básicos, las líneas de unión que establecen las conexiones no necesariamente llevan puntas de flechas, como también pueden contener flechas bidireccionales. Más que mostrar las relaciones existentes entre los elementos de un tema, un esquema realmente se realiza con la finalidad de resumir un contenido mostrándolo gráficamente de manera organizada y sistematizada (Grisolía, s. f.).

\section{Las tecnologías de información y comunicación (TIC) como herramientas para la enseñanza y el aprendizaje}

A lo largo del tiempo ha sido posible evidenciar numerosos avances científicos y tecnológicos que han causado un gran impacto en diversos ámbitos de la sociedad, sin lugar a dudas, la generación actual es prueba de ello, pues ha incorporado a su cotidianidad el uso de dichos avances para la ejecución de un sinfín de actividades. En el campo educativo el papel de la tecnología se ha incrementado progresivamente, hasta tal punto que en algunos niveles educativos se han ido desplazando las investigaciones y consultas en fuentes bibliográficas tradicionales, esto se debe principalmente a la facilidad que representa para el estudiantado el uso de las herramientas tecnológicas que incorporan los distintos sistemas representativos.

Es preciso señalar que, debido a esto, se han desarrollado las tecnologías de la información y comunicación, conocidas comúnmente como las TIC. Belloch (s. f.) dice al respecto:

Las TIC se desarrollan a partir de los avances científicos producidos en los ámbitos de la informática y las telecomunicaciones... son el conjunto de tecnologías que permiten el acceso, producción, tratamiento y comunicación de información presentada en diferentes códigos (texto, imagen, sonido, ...). (p. 1)

La educación como proceso formador debe estar enfocado en la búsqueda permanente de adaptaciones al contexto histórico y social, por tal motivo, el personal docente actual debe apropiarse de estrategias que permitan incorporar la tecnología a su práctica profesional con la finalidad de enriquecer el proceso de enseñanza y aprendizaje. Además, las herramientas tecnológicas son de gran utilidad al momento de incorporar elementos que den respuesta a los distintos sistemas representativos mediante los cuales los individuos aprenden. Para Bartolomé (1997) citado en García-Vera y Pastor (1997), las TIC encuentran:

su papel como una especialización dentro del ámbito de la Didáctica y de otras ciencias aplicadas de la Educación, refiriéndose especialmente al diseño, desarrollo y aplicación 
de recursos en procesos educativos, no únicamente en los procesos instructivos, sino también en aspectos relacionados con la Educación Social y otros campos educativos.

Estos recursos se refieren, en general, especialmente a los recursos de carácter informático, audiovisual, tecnológicos, del tratamiento de la información y los que facilitan la comunicación. (p. 3)

El empleo de las TIC para el proceso educativo en las aulas de clase y fuera de ellas permite que estudiantes y docentes compartan un lenguaje, que el estudiantado se interese más en aprender, y que cada docente adapte, a sus necesidades y características específicas, los recursos digitales para el aprendizaje. Además de esto, las TIC facilitan la comunicación no presencial a través de redes sociales, correos electrónicos, blogs, páginas web, audioconferencias, videoconferencias, entre otros; lo que representa una ventaja en el aprovechamiento del tiempo.

Ahora bien, si está en las posibilidades del personal docente y la institución cuenta con las equipos necesarios, se debería hacer uso de las tecnologías de información y comunicación mediante programas para construcción de presentaciones con diapositivas, lo que permite un menor esfuerzo y un mejor resultado en el acabado de los recursos (si son utilizados correctamente), puesto que empleando estos programas no solo se pueden realizar presentaciones con texto e imágenes relativas, sino que también es posible incorporar cualquiera de los recursos didácticos antes mencionados para la estimulación visual del estudiantado; proyección de películas o videos (medios audiovisuales). Estos pueden ser bastantes eficaces al combinar el aprendizaje visual con el auditivo lo que aumenta las posibilidades de que el aprendizaje sea significativo, al mismo tiempo, brinda la oportunidad al personal docente de explicar un tema desconocido por sus estudiantes o con un nuevo enfoque, profundizando en este mismo después de la proyección del medio audiovisual.

Es importante que el cuerpo docente no abuse del uso de estos programas o medios audiovisuales, desde ningún concepto debe impartir una clase consistente únicamente en la lectura de diapositivas, estas no debe cargarse excesivamente de texto, pues quedaría entredicho el dominio de contenido del docente, además de que el mensaje no llegaría de manera eficaz al estudiantado, ni tampoco puede dedicarse a la simple proyección de medios audiovisuales sin una interpretación, explicación, profundización o discusión de estos.

No es apropiado que el personal docente utilice el mismo tipo de recurso didáctico a lo largo de su labor profesional para temas, tiempos y públicos diferentes, ni mucho menos para diversas clases dirigidas al mismo público. El personal docente debe experimentar, ensayar y, si es necesario, errar, para poder fortalecer cualquier debilidad que se pueda presentar. 
doi: http://dx.doi.org/10.15359/ree.21-2.22

URL: http://www.una.ac.cr/educare

CORREO: educare@una.cr

\section{Conclusiones y recomendaciones}

Los órganos sensoriales desempeñan un papel fundamental en el aprendizaje del estudiantado, y a pesar de que los sistemas representativos o sentidos prioritarios para la percepción del entorno pueden diferir entre un individuo y otro, el ser humano a lo largo del tiempo ha ideado recursos, técnicas y estrategias de enseñanza destinadas a los distintos estilos de aprendizaje (visual, auditivo, kinestésico). Aunque los órganos sensoriales son los que permiten captar la información, es en el cerebro donde esa información en decodificada, procesada, asimilada y almacenada mediante procesos complejos de sinapsis neuronal. El aprendizaje es, pues, el resultado de importantes procesos biológicos.

Es de suma relevancia que la totalidad de docentes, y aún más los que enseñan ciencias biológicas, adapten sus clases a estas realidades, considerando que los recursos didácticos son herramientas útiles que pueden facilitar el aprendizaje de sus estudiantes, al estimular de manera positiva los órganos sensoriales y sus respectivas áreas en la corteza cerebral. Está comprobado que la vista es un sentido trascendental en la mayoría de los seres humanos al momento de aprender, por lo que esta información debe ser tomada en cuenta al planificar las estrategias para impartir una clase.

Entre los recursos didácticos para la estimulación visual del estudiantado en ciencias biológicas podemos encontrar una amplia gama con características específicas, algunos de ellos son: ilustraciones esquemáticas, modelos didácticos, mapas conceptuales, mapas mentales, esquemas. Conociendo las características de estos recursos, es posible seleccionar adecuadamente cuáles utilizar para determinados aspectos de un contenido de acuerdo con su naturaleza, combinando entonces el recurso visual con la explicación oral que ofrece cada docente para la estimulación visual y auditiva de sus estudiantes.

El uso adecuado de las tecnologías de información y comunicación puede convertirse en una herramienta de gran utilidad para la incorporación de recursos didácticos visuales, e incluso recursos audiovisuales para la enseñanza. Esto, a su vez, despierta el interés estudiantil, pues en la actualidad se desenvuelven en un contexto histórico y social en el que la tecnología ha proliferado en gran manera.

La educación es un aspecto fundamental en la vida de cada persona y la educación formal está a cargo de docentes, quienes deben estar conscientes de la importancia que tiene su labor en la formación de los individuos que constituyen la sociedad, por lo tanto, el personal docente debe estar comprometido con las funciones que cumple dentro de cualquier institución educativa independientemente del nivel del sistema para el cual trabaje. Es importante que el personal docente sea autocrítico y reflexivo en su práctica profesional, que escudriñe las técnicas y estrategias que aplica para lograr un aprendizaje significativo en sus estudiantes, de tal manera que pueda detectar las posibles debilidades y ocuparse de convertirlas en fortalezas. 
A pesar de que en muchos casos las expectativas docentes en cuanto al rendimiento académico de sus estudiantes son muy altas en comparación con los resultados que se obtienen en la realidad, es necesario tener presente que se debe dar lo mejor de sí en cada clase, no dejarse desanimar por las circunstancias, recordar que aunque sean muchos o pocos sujetos aquellos que estén realmente interesados en lo que el personal docente pretende enseñar, de igual manera lo correcto es hacer el trabajo con excelencia, pues eso es lo debe caracterizar a quien se dedica al arte de enseñar.

\section{Referencias}

Ausubel, D. P., Novak, J. D. y Hanesian, H. (1983). Psicología educativa: Un punto de vista cognoscitivo ( $\left.2^{\mathrm{a}} \mathrm{ed}\right)$. México: Trillas.

García-Vera, A. B. y Pastor, C. A. (1997). ¿Qué es tecnología educativa?: Autores y significados. Píxel-bit, 9, 1-11. Recuperado de http://acdc.sav.us.es/ojs/index.php/pixelbit/article/ view/567/395

Belloch, C. (s. f.). Las tecnologías de la información y comunicación (T.I.C). Recuperado de http:// www.uv.es/ bellochc/pdf/pwtic1.pdf

Castello, L. A. y Mársico, C. T. (1995). Diccionario etimológico de términos usuales en la praxis docente. Buenos Aires: Altamira. Recuperado de http://www.terras.edu.ar/ biblioteca/35/35CASTELLO-Luis-MARSICO-Claudia-Que-es-educar.pdf

De Bono, E. (1994). El pensamiento creativo. El poder del pensamiento lateral para la creación de nuevas ideas. Barcelona: Paidós.

De la Parra, E. (2004). Herencia de vida para tus hijos: Crecimiento integral con técnicas PNL. México: Grijalbo.

Fuentes, R. (2012). Anatomía, fisiología y ciencias de la salud (5a ed.). México: Trillas.

Gómez, J. J. (Coord.) (1995). Las lecciones del dibujo. Madrid: Cátedra.

González, F. M. (1992). Los mapas conceptuales de J. D. Novak como instrumentos para la investigación en didáctica de las ciencias experimentales. Enseñanza de las ciencias, 10(2), 148-158. Recuperado de http://www.raco.cat/index.php/Ensenanza/article/ download/39815/93182

Grisolía, M. (s. f.) ¿Qué es un recurso didáctico? Recuperado de http://webdelprofesor.ula.ve/ humanidades/marygri/recursos.php 
doi: http://dx.doi.org/10.15359/ree.21-2.22

URL: http://www.una.ac.cr/educare

CORREO: educare@una.cr

Hickman, C. P., Jr., Roberts, L. S., Keen, S., Larson, A., I'Anson, H. y Eisenhour, D. J. (2006). Principios integrales de zoología (13 ed.). Madrid: McGraw-Hill.

Latarjet, M. y Ruiz, A. (2004). Anatomía humana (Tomo 1, 4ª ed.). Barcelona: Editorial Médica Panamericana.

López, I. (2012). Recursos para el aprendizaje (2a ed.) Caracas: Universidad Pedagógica Experimental Libertador.

Menchén, F. (1998). Descubrir la creatividad. Desaprender para volver a aprender. Madrid: Pirámide.

Muñoz, J. (1994). El pensamiento creativo. Desarrollo del programa Xènius. Barcelona: Octaedro.

O'Connor, J. y Seymour, J. (1995). Introducción a la PNL (8a ed.). Barcelona: Urano.

Solomon, E. P., Berg, L. R. y Martin, D. W. (2013). Biología (9a ed.). México: Cengage Learning.

Yokochi, C., Rohen, J. W. y Weinreb, E. L. (1991). Atlas fotográfico de anatomía del cuerpo humano ( $3^{\mathrm{a}}$ ed.). México: McGraw-Hill Interamericana. 